\title{
The whole 9 years
}

\section{Ian Olver considers his time at Cancer Council Australia and suggests embracing cancer treatment, prevention and research provides a comprehensive cancer control experience}

$\mathrm{T}$ he transition from clinical oncology to public policy as part of my role at Cancer Council Australia was challenging, but it used, as background, the patient-centred focus of clinical practice. Good policy affects millions at a time as compared to influencing one patient at a time in practice. I came to appreciate the importance of federal governments that were prepared to focus not only on short-term policy goals but also support initiatives where the benefits would not be realised until the longer term. In cancer control that often translates to funding prevention measures as well as treatment.

Probably the most satisfying of the Cancer Council's advocacy goals achieved during my time as chief executive officer was when successive governments supported the introduction of a bowel cancer screening program for Australia. Although progress was slow, there is now a commitment to completing the implementation of the program by 2020. Conservative estimates show that this program alone will save at least 500 Australian lives each year. ${ }^{1}$

The most effective anticancer measure remains tobacco control. Here we could join with a well established team of campaigners, some lifelong, to continue the battle with the tobacco industry through public education and advocating for legislative support. It is pleasing to see the prevalence of adult smoking is down to $12.8 \%$ in 2013 from $24.3 \%$ in $1991 .^{2}$ The most effective strategy for reducing tobacco consumption is price, and the large tax increase in 2010 and the intended four annual $12.5 \%$ tax increases (of which there are two to go) should ensure that the goal of reducing the smoking rate to $10 \%$ by 2018 is reached. However, the most spectacular anti-tobacco measure taken by the federal government was the introduction of plain packaging in 2010, led by the then minister for health, Nicola Roxon.

This strategy had the long-term goal of decreasing the attractiveness of cigarettes to potential young smokers. However, because Australia was the first country to introduce plain packaging, the legal resources of the tobacco industry were going to be focused on fighting it in this country. The stakes and the risks were high. The outcome was significant in that a government seeking to protect its citizens against a harmful product could not be legally outmanoeuvred by the tobacco industry that was trying to profit from the same citizens despite the adverse health effects of their product. This has international repercussions for tobacco control, despite the further legal challenges remaining. ${ }^{3-5}$

Whereas federal governments embraced tobacco control, there has been reluctance by both the major parties to address the next major contributor to cancer, and that is obesity, which includes the matters of diet, alcohol consumption and exercise. Concerns about freedom of choice in such matters were argued as precluding government interference, either through policy options such as restricting junk-food advertising to children or taxing high-sugar drinks. Even a frontof-pack labelling system to enable people to be more easily informed about the nutritional value of food, which facilitates that free choice, just stuttered into existence. Often the term "nanny state" is used to justify government non-interference, but surely, in the case of a multimillion dollar junk-food advertising campaign directed at children, a national government would want to be a nanny to protect Australia's greatest resource?

\section{"We need to collaborate widely at state, national and international levels to be part of research projects that will have the greatest impact"}

Luck can also play a role in advocacy for public policy and can occur at the most unexpected times. In the midst of the global financial crisis in 2009, it seemed as though asking for new funding for any cancer-control initiative would be likely to be unsuccessful. However, there was one item on our advocacy agenda that aligned with the then federal government's desire to stimulate the economy and create employment - and that was the building of regional cancer centres. In the 2009-10 federal Budget, the government announced $\$ 560$ million would be allocated from the Health and Hospitals Fund for new or expanded regional cancer services. ${ }^{6}$ This funding helped redress one of the disparities in cancer care - that of remoteness - where the cancer outcomes for people who live remotely are not as good as those for people who live in large cities.

The other great disparity in cancer control is the poorer outcomes for Aboriginal and Torres Strait Islanders. As part of Cancer Council Australia, I worked with some very motivated Aboriginal health experts, particularly when we formed NICaN (the National Indigenous Cancer Network), which brought together the Menzies School of Health Research, the Lowitja Institute, Australian Indigenous HealthInfoNet and Cancer Council Australia as partners. There is still much work to be done in this area, but continuing to seek the evidence on which to base a solution seems to embrace the correct strategy. 
It is always satisfying when Australia is the innovator. Ian Frazer, who served as President of the Board of Cancer Council Australia for part of my time as $\mathrm{CEO}$, had a major role in developing the human papillomavirus (HPV) vaccine. Australia already had an enviable record in terms of how effective the Pap test had been in reducing the incidence and mortality from cancer of the cervix, but this record was further strengthened when successive health ministers announced the National HPV Vaccination Program for girls in 2007 and, subsequently, in a world first, extended it to boys. Over the next two decades, deaths from cancer of the cervix will become a rarity.

The opportunity for innovation within Cancer Council Australia came in the area of treatment guidelines. These had been published by the Cancer Council in the major cancers for many years, but the printed documents became rapidly out of date and were costly to circulate. I sought a digital solution, and we developed a wiki platform for guidelines that allowed easy updating and widespread dissemination as well as being able to track the use of the guidelines. ${ }^{7}$ It made the whole process more cost-effective because we could keep the writing teams engaged and have them evaluate new papers and change their sections of the guidelines as new evidence became available. In terms of cost, the guidelines would be unaffordable if it were not for the generosity of the cancer experts who voluntarily participate in the expert groups to appraise articles and write the evidence-based recommendations - this is an impressive commitment to ensuring best practice across their specialties. Cancer Council Australia is now evaluating the use of educational modules with the guidelines to reinforce their use in practice. As a result of the Cancer Council's involvement with the Guidelines International Network, the Cancer Council's staff were able to share literature searches with international colleagues.

We also used the wiki platform at Cancer Council Australia to produce a free online textbook for students $^{8}$ to support the Ideal Oncology Curriculum. Both the online textbook and the Ideal Oncology Curriculum were written by Cancer Council Australia's Oncology Education Committee, which has representation from all the Australian universities with medical schools. Likewise, Cancer Council Australia put the National Cancer Prevention Policy on a wiki platform so that the Cancer Council always had the most up-to-date evidence base to underpin our advocacy agenda and our media and other public statements. ${ }^{9}$ The joy of producing this national document was in being able to draw on the expertise available to all the state and territory Cancer Councils.

Funding cancer research is a priority for all the Cancer Councils. Two concerns that Cancer Council Australia explored in common with the other cancer charities were establishing both the research priorities and the best balance between investigator-initiated research and priority-driven research. It was also important to measure the impact of the research investment to optimise the outcomes and ensure the best use of donated funds.

I have been a cancer researcher during the span of my clinical career and was able to continue with research during my years at the Cancer Council. I moved from participating in new drug clinical trials to more psychosocial research, thereby embracing both quantitative and qualitative methods. A lesson I learnt from being involved in research on a national level was that there are greater opportunities for collaboration when you are not constrained by state boundaries. I was able to collaborate on projects with multiple universities, and these broader collaborations also seemed to increase the success rate of obtaining grant funding.

In my recent move to a research position as director of the Sansom Institute for Health Research at the University of South Australia with the brief to build upon the Institute's cancer research capability, all the above issues are still relevant. In deciding on the direction for research, we must consider what research will have international importance and in which research Australia can be internationally competitive. We need to collaborate widely at state, national and international levels to be part of research projects that will have the greatest impact.

Australian cancer researchers also need to learn from other disciplines. Venture capitalists are often attracted by projects that, if successful, will shake up a field rather than just hold the promise of incremental change. Cancer research portfolios should reflect some of that disruptive philosophy. There may be new strategies to fund research, in particular, such as the crowdfunding strategies that are making an impact on the music industry and commercial fundraising. Would the public become personally involved and excited about sponsoring a researcher or an innovative cancer research project? There are exciting prospects for how cancer research could develop - perhaps over my next 9 years?

Competing interests: No relevant disclosures.

Provenance: Commissioned; not externally peer reviewed.

References are available online at www.mja.com.au. 
1 Pignone MP, Flitcroft KL, Howard K, et al. Costs and costeffectiveness of full implementation of a biennial faecal occult blood test screening program for bowel cancer in Australia. Med J Aust 2011; 194: 180-185.

2 Australian Institute of Health and Welfare. National Drugs Strategy Household Surveys (NDSHS). http://aihw.gov.au/ alcohol-and-other-drugs/ndshs (accessed Jan 2015).

3 Nick Miller. As Europe adopts Australia's plain packaging reforms, big tobacco fights back. Sydney Morning Herald 2015; 22 Mar. http://www.smh.com.au/world/as-europe-adoptsaustralias-plain-packaging-reforms-big-tobacco-fights-back20150321-lm3bwk.html (accessed Mar 2015).

4 Australian Government Department of Health. Evaluation of tobacco plain packaging in Australia. http://www.health.gov. au/internet/main/publishing.nsf/Content/tobacco-plainpackaging-evaluation (accessed Mar 2015).

5 Young JM, Stacey I, Dobbins TA, et al. Association between tobacco plain packaging and Quitline calls: a populationbased, interrupted time-series analysis. Med J Aust 2014; 200: 29-32.

6 Australian Government Department of Health. Health and Hospitals Fund (HHF). 6 March 2015. http://www.health.gov. au/hhf (accessed Mar 2015).

7 Cancer Council Australia. Cancer guidelines wiki. http://wiki. cancer.org.au/australia/guidelines (accessed Jan 2015).

8 Cancer Council Australia. Clinical oncology for medical students. http://wiki.cancer.org.au/ oncologyformedicalstudents/clinical_oncology_for_medical_ students (accessed Jan 2015).

9 Cancer Council Australia. National Cancer Prevention Policy. http://www.cancer.org.au/policy-and-advocacy/preventionpolicy/national-cancer-prevention-policy.html (accessed Jan 2015). 